\title{
Redox Buffering of Hypochlorous Acid by \\ Thiocyanate in Physiologic Fluids
}

\author{
Michael T. Ashby, ${ }^{*}$, Amy C. Carlson, and M. Jared Scott \\ Department of Chemistry and Biochemistry, University of Oklahoma, 630 \\ Parrington Oval, Norman, OK 73019
}

Submitted October 9, 2004; E-mail: mashby@ou.edu

\section{SUPPORTING INFORMATION}

\section{Experimental Procedures}

General. Reagents were obtained from Sigma-Aldrich and used as received. Water was doubly-distilled in glass. The concentrations of stock solutions of hypochlorite were determined iodometrically. The concentration of hypochlorite in solutions that were prepared from the stock solution were confirmed spectrophometrically $\left(\varepsilon\left(\mathrm{OCl}^{-}\right)_{292 \mathrm{~nm}}=350 \mathrm{M}^{-1} \mathrm{~cm}^{-1}\right)$. All manipulations were carried out under atmospheres of prepurified $\left(\mathrm{O}_{2}\right.$ and $\mathrm{CO}_{2}$-free $)$ argon or nitrogen using Schlenk lines or glove boxes. Electronic spectra were measured using a HP 8452A diode array spectrophotometer or the monochromator of a HI-TECH SF-61 DX2 stopped-flow instrument with a Xe arc lamp. Schlenk cuvettes were employed when making measurements with the HP 8452A. The mixing unit of the SF-61 DX2 was located in a Vacuum Atmospheres glove box 
that is equipped with a MO-40M purifier. Temperature control of the SF-61 DX2 was maintained with a Lauda RC-20 circulator.

Preparation of Base Solutions. Caution: The following procedure is extremely dangerous. The reaction of sodium metal with water, even when the temperature is controlled with liquid nitrogen, is highly exothermic and it proceeds with the evolution of copious amounts of potentially explosive hydrogen gas. This procedure should only be followed by individuals who have considerable experience with Schlenk methods and the handling of such reactions. To avoid contamination with carbonate, a stock base solution was synthesized by reaction of sodium metal with water using Schlenk techniques. Sodium metal was cut from a larger block and successively washed with methanol (to remove oxide), ether, and pentane. The pieces of sodium were added to a three-neck round-bottom flask fitted with a reflux condenser and a Schlenk adaptor under an atmosphere of prepurified argon. Xylene was added and sodium sand was prepared by rapidly mechanically stirring a molten suspension of sodium metal in refluxing xylene. The stirring was stopped, and after cooling to room temperature, the xylene was removed with a cannula, the sand was washed with pentane, and it was dried under vacuum. Carbonate-free solutions of $\mathrm{NaOH}$ were prepared by adding sodium sand to distilled water that was freeze-pumped-thawed in a Schlenk flask twice and left under an atmosphere of argon. The reaction was controlled with a liquid nitrogen bath. Since $\mathrm{pH}$ electrodes are subject to significant alkaline error at $\mathrm{pH}$ greater than 11 , hydroxide ion concentration was established by titration with acid. The Schlenk flask was transferred to a glovebox under an atmosphere of nitrogen and three aliquots (diluted 10:1 using volumetric pipets) were titrated with primary standard potassium hydrogen phthalate (KHP) using phenolphthalene as an indicator. Because the temperature in the glovebox was $36{ }^{\circ} \mathrm{C}$ and the pipets and buret were calibrated at $20{ }^{\circ} \mathrm{C}$, the 
titration was repeated outside the glovebox using solutions that were prepared in the glovebox. Exactly the same result was obtained (no doubt due to compensating effects on both the pipets and the buret that was used). Using $25 \mathrm{~mL}$ volumetric pipets, a gradient of $\left[\mathrm{OH}^{-}\right]$was prepared by successive $1: 1$ dilutions with $1 \mathrm{M} \mathrm{NaCl}$ in water that had been freeze-pumped-thawed three times before transferring to the glovebox. Thus a $\mathrm{OH}^{-}$gradient from ca. 0.0005 to $1 \mathrm{M}$ was prepared with $\mu=1$.

Single-mixing stopped-flow measurements. The data that are summarized in Figures 1 and S3 were collected in single-mixing mode. The observed rate constants are summarized in Tables $\mathrm{S} 1$ and S2. An example of a typical trace at $300 \mathrm{~nm}$ that reflects the first-order disappearance of $\mathrm{OCl}^{-}$is illustrated in Figure S1. Figure 1 and the data of Table S1 demonstrate a first-order dependence on $\left[\mathrm{H}^{+}\right]$(inverse dependence on $\left[\mathrm{OH}^{-}\right]$). Figure $\mathrm{S} 2$ and the data in Table S2 demonstrate a first-order dependence on $\left[\mathrm{SCN}^{-}\right]$.

Derivation of rate law. The rate constant $k_{3}$ can be derived using the steady-state approximation:

$$
\begin{aligned}
& \mathrm{OCl}^{-}+\mathrm{H}^{+} \underset{\mathrm{k}_{\mathrm{a}}}{\stackrel{\mathrm{k}_{-\mathrm{a}}}{=}} \mathrm{HOCl}^{-} \\
& \mathrm{HOCl}+\mathrm{SCN}^{-} \stackrel{\mathrm{k}_{3}}{\longrightarrow} \mathrm{Cl}^{-}+\mathrm{OSCN}^{-}+\mathrm{H}^{+}
\end{aligned}
$$

$$
\begin{aligned}
& \frac{+\mathrm{d}[\mathrm{HOCl}]}{\mathrm{dt}}=\mathrm{k}_{-\mathrm{a}}\left[\mathrm{H}^{+}\right][\mathrm{OCl}-]-\mathrm{k}_{a}[\mathrm{HOCl}]-\mathrm{k}_{3}[\mathrm{HOCl}]\left[\mathrm{SCN}^{-}\right]=0 \\
& =\mathrm{k}_{-\mathrm{a}}\left[\mathrm{H}^{+}\right]\left[\mathrm{OCl}^{-}\right]-\left(\mathrm{k}_{\mathrm{a}}+\mathrm{k}_{3}\left[\mathrm{SCN}^{-}\right]\right)[\mathrm{HOCl}] \\
& {\left[\mathrm{HOCl}_{\mathrm{ss}}=\frac{\mathrm{k}_{-\mathrm{a}}\left[\mathrm{H}^{+}\right]\left[\mathrm{OCl}^{-}\right]}{\mathrm{k}_{\mathrm{a}}+\mathrm{k}_{\mathrm{a}}\left[\mathrm{SCN}^{-}\right]}\right.} \\
& \frac{+\mathrm{d}\left[\mathrm{OSCN}^{-}\right]}{\mathrm{dt}}=\mathrm{k}_{3}\left[\mathrm{HOCI}\left[\mathrm{SCN}^{-}\right]=\frac{\mathrm{k}_{-\mathrm{a}} \mathrm{k}_{3}\left[\mathrm{H}^{+}\right]\left[\mathrm{OCl}^{-}\right]\left[\mathrm{SCN}^{-}\right]}{\mathrm{k}_{\mathrm{a}}+\mathrm{k}_{2}\left[\mathrm{SCN}^{-}\right]}\right.
\end{aligned}
$$


Assuming $\mathrm{k}_{\mathrm{a}}>\mathrm{k}_{3}\left[\mathrm{SCN}^{-}\right]$(i.e., the reaction is first order in $\mathrm{SCN}^{-}$):

$$
\begin{aligned}
& \frac{+\mathrm{d}\left[\mathrm{OCl}^{-}\right]}{\mathrm{dt}}=\mathrm{k}_{\text {eff }}\left[\mathrm{OCl}^{-}\right]=\left(\mathrm{k}_{-\mathrm{a}} \mathrm{k}_{3} / \mathrm{k}_{\mathrm{a}}\right)\left[\mathrm{H}^{+}\right]\left[\mathrm{OCl}^{-}\right]\left[\mathrm{SCN}^{-}\right] \\
& \left(\mathrm{k}_{-\mathrm{a}} / \mathrm{k}_{\mathrm{a}}\right)=1 / \mathrm{K}_{\mathrm{a}}=2.51 \times 10^{7} \mathrm{M}^{-1}(\text { at } \mu=1) \\
& \mathrm{k}_{\text {eff }}=\mathrm{k}_{3}\left[\mathrm{H}^{+}\right]\left[\mathrm{SCN}^{-}\right] / \mathrm{K}_{\mathrm{a}} \\
& \mathbf{k}_{\mathbf{3}}=\frac{\mathbf{K}_{\mathbf{a}} \mathbf{k}_{\text {eff }}}{\left[\mathrm{H}^{+}\right]\left[\mathrm{SCN}^{-}\right]}
\end{aligned}
$$

The same result is obtained if one assumes that $\mathrm{HOCl}$ and $\mathrm{OCl}^{-}$are in rapid equilibrium and $\mathrm{K}_{\mathrm{a}}$ $>\left[\mathrm{H}^{+}\right]$, also a valid assumption for the $\mathrm{pH}$ range that was employed in this study.

Double-mixing stopped-flow measurements. The rate of reaction of the first mixing and the optimum aging times were independently determined in single-mixing mode. The stabilities of $\mathrm{OCl}^{-}$and $\mathrm{SCN}^{-}$in the $\mathrm{pH}$ range of 10-13.5 in the presence of irradiation by the Xe arc lamp were independently established. Although the kinetics were monitored monochromatically, the entire UV spectrum was scanned by the monochromator after the second mixing cycle. The concentrations that were employed in each of the syringes and the sequence of mixing are illustrated in Scheme S1. The HI-TECH SF61 DX2 employs four syringes in double-mixing mode. After 1:1 mixing of the contents of the first two syringes with a deposition of the resulting solution into an aging loop, the contents of that aging loop are driven out of the loop by a third syringe while mixing with the contents of the fourth syringe. Thus, the content of the aging loop is replaced with the content of the third syringe with a 1:1 mixing of the content of the aging syringe and the content of the fourth syringe. We employed $0.1 \mathrm{M} \mathrm{NaOH}$ in the third syringe when generating hypothiocyanite in the first mixing cycle and $0.5 \mathrm{M} \mathrm{HCl}$ in the third syringe when chlorine was generated in the first mixing cycle. The spectra that were measured for the two double-mixing sequences of Scheme S1 and illustrated in Figure S3. 
Modeling of rate equations. Figure 2 was generated from data that were computed using rate equations that were programmed into Mathematica 5.0. The input files and representative plots are available from the author upon request. The simultaneous differential equations were in general solved by numerical methods, although closed solutions were possible in some cases in some cases where the boundary conditions (as defined in the text) simplified the equations. No assumptions were made to simplify the rate laws (e.g., steady-state approximations) except that the Brønsted acid-base chemistry was assumed to be facile with respect to all other kinetic processes and the concentration of $\mathrm{Cl}^{-}$was assumed to remain constant by virtue of its high concentration $(100 \mathrm{mM})$. Dynamic changes in concentration were taken into consideration for all other species:

$\frac{\partial[\mathrm{MPO}]}{\partial \mathrm{t}}=-\mathrm{k}_{1}[\mathrm{MPO}]\left[\mathrm{H}_{2} \mathrm{O}_{2}\right]+\mathrm{k}_{-1}[\mathrm{MPO}-\mathrm{I}]+\mathrm{k}_{2}^{\mathrm{Cl}^{-}}[\mathrm{MPO}-\mathrm{I}]\left[\mathrm{Cl}^{-}\right]_{0}+\mathrm{k}_{2}^{\mathrm{SCN}^{-}}[\mathrm{MPO}-\mathrm{I}]\left[\mathrm{SCN}^{-}\right]$
$\frac{\partial[\mathrm{MPO}-\mathrm{I}]}{\partial \mathrm{t}}=\mathrm{k}_{1}[\mathrm{MPO}]\left[\mathrm{H}_{2} \mathrm{O}_{2}\right]-\mathrm{k}_{-1}[\mathrm{MPO}-\mathrm{I}]-\mathrm{k}_{2}^{\mathrm{Cl}^{-}}[\mathrm{MPO}-\mathrm{I}]\left[\mathrm{Cl}^{-}\right]_{0}-\mathrm{k}_{2}^{\mathrm{SCN}^{-}}[\mathrm{MPO}-\mathrm{I}]\left[\mathrm{SCN}^{-}\right]$

$\frac{\partial\left[\mathrm{H}_{2} \mathrm{O}_{2}\right]}{\partial \mathrm{t}}=-\mathrm{k}_{1}[\mathrm{MPO}]\left[\mathrm{H}_{2} \mathrm{O}_{2}\right]+\mathrm{k}_{-1}[\mathrm{MPO}-\mathrm{I}]$

$\frac{\partial\left[\mathrm{SCN}^{-}\right]}{\partial \mathrm{t}}=-\mathrm{k}_{2}^{\mathrm{SCN}^{-}}[\mathrm{MPO}-\mathrm{I}]\left[\mathrm{SCN}^{-}\right]-\frac{\mathrm{k}_{3}\left[\mathrm{OCl}^{-}\right]\left[\mathrm{SCN}^{-}\right]}{\mathrm{K}_{\mathrm{a}}}$

$\frac{\partial\left[\mathrm{OCl}^{-}\right]}{\partial \mathrm{t}}=\mathrm{k}_{2}^{\mathrm{Cl}^{-}}[\mathrm{MPO}-\mathrm{I}]\left[\mathrm{Cl}^{-}\right]_{0}-\frac{\mathrm{k}_{3}\left[\mathrm{OCl}^{-}\right]\left[\mathrm{SCN}^{-}\right]}{\mathrm{K}_{\mathrm{a}}}$

$\frac{\partial\left[\mathrm{OSCN}^{-}\right]}{\partial \mathrm{t}}=\mathrm{k}_{2}^{\mathrm{SCN}^{-}}[\mathrm{MPO}-\mathrm{I}]\left[\mathrm{SCN}^{-}\right]+\frac{\mathrm{k}_{3}\left[\mathrm{OCl}^{-}\right]\left[\mathrm{SCN}^{-}\right]}{\mathrm{K}_{\mathrm{a}}}$ 


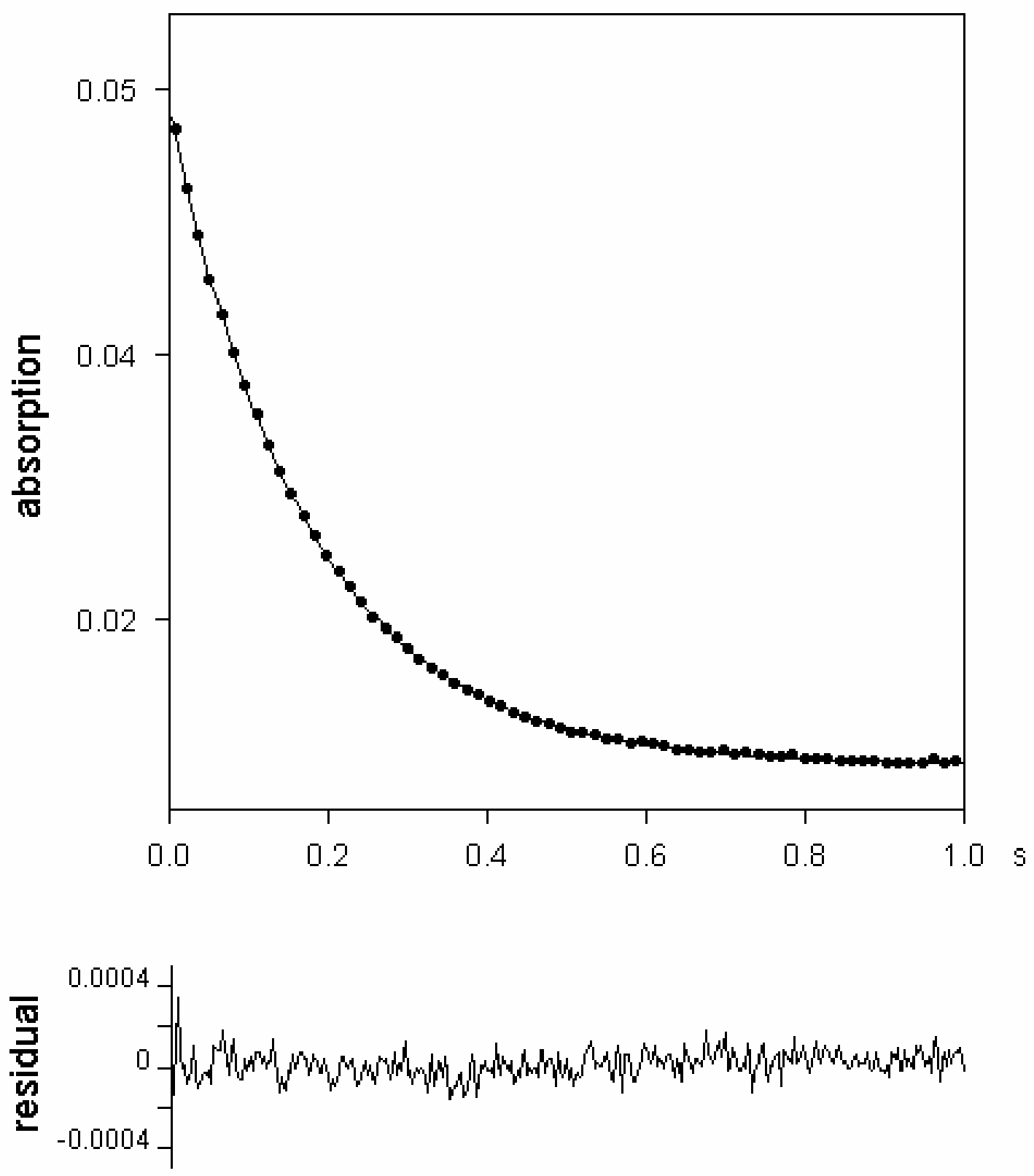

Figure S1. Typical trace at $300 \mathrm{~nm}$ (illustrating $20 \%$ of the data) reflecting the disappearance of $\mathrm{OCl}^{-}$for the reaction of $100 \mu \mathrm{M} \mathrm{NaOCl}$ with $1 \mathrm{mM} \mathrm{NaSCN}$ $\left(\left[\mathrm{OH}^{-}\right]=1.6 \times 10^{-2}, \mathrm{pH}=12, \mu=1\right)$ fit to a first-order equation and residual. 


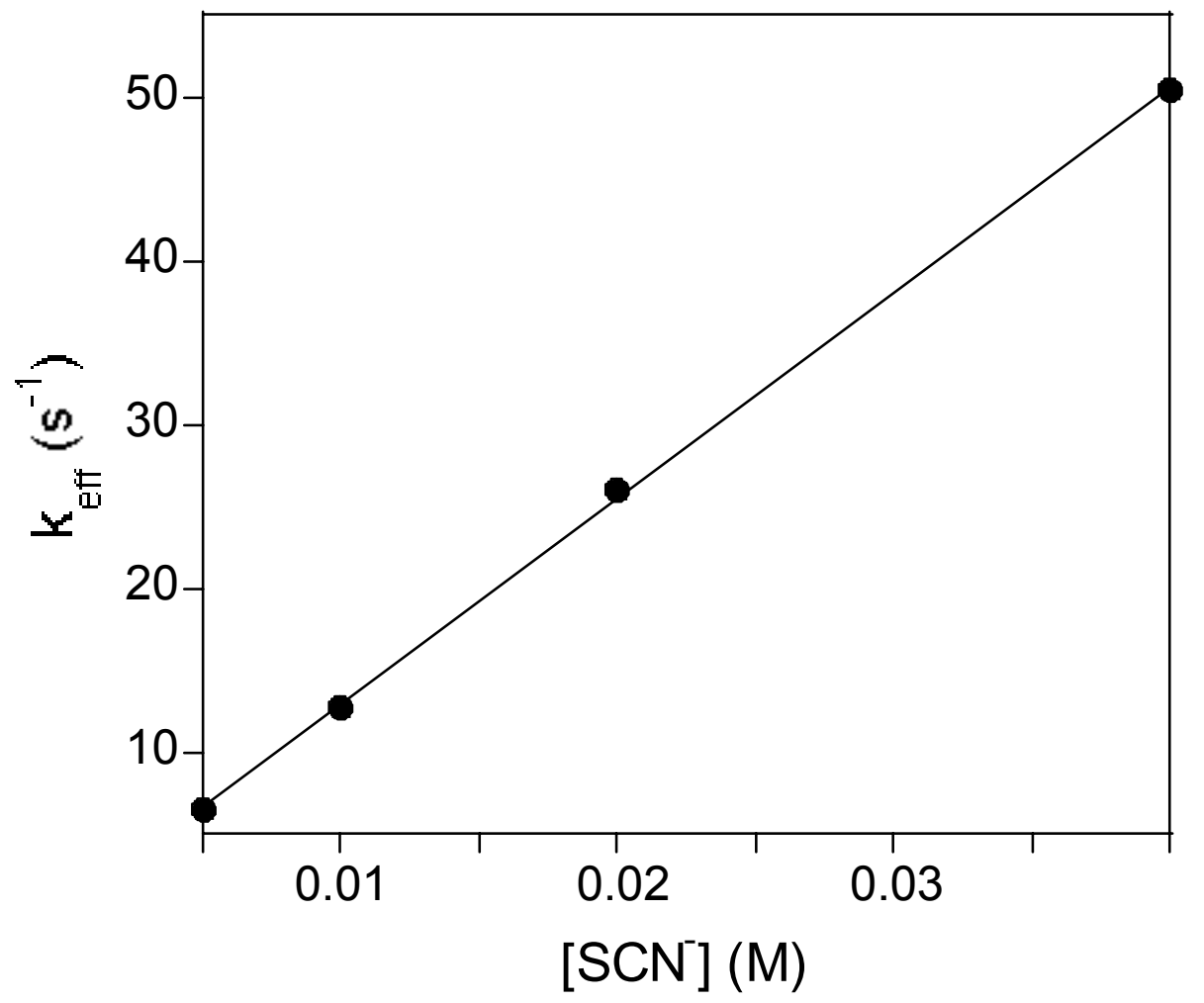

Figure S2. First-order relationship between $\mathrm{k}_{\mathrm{eff}}$ and $\left[\mathrm{SCN}^{-}\right]$ 


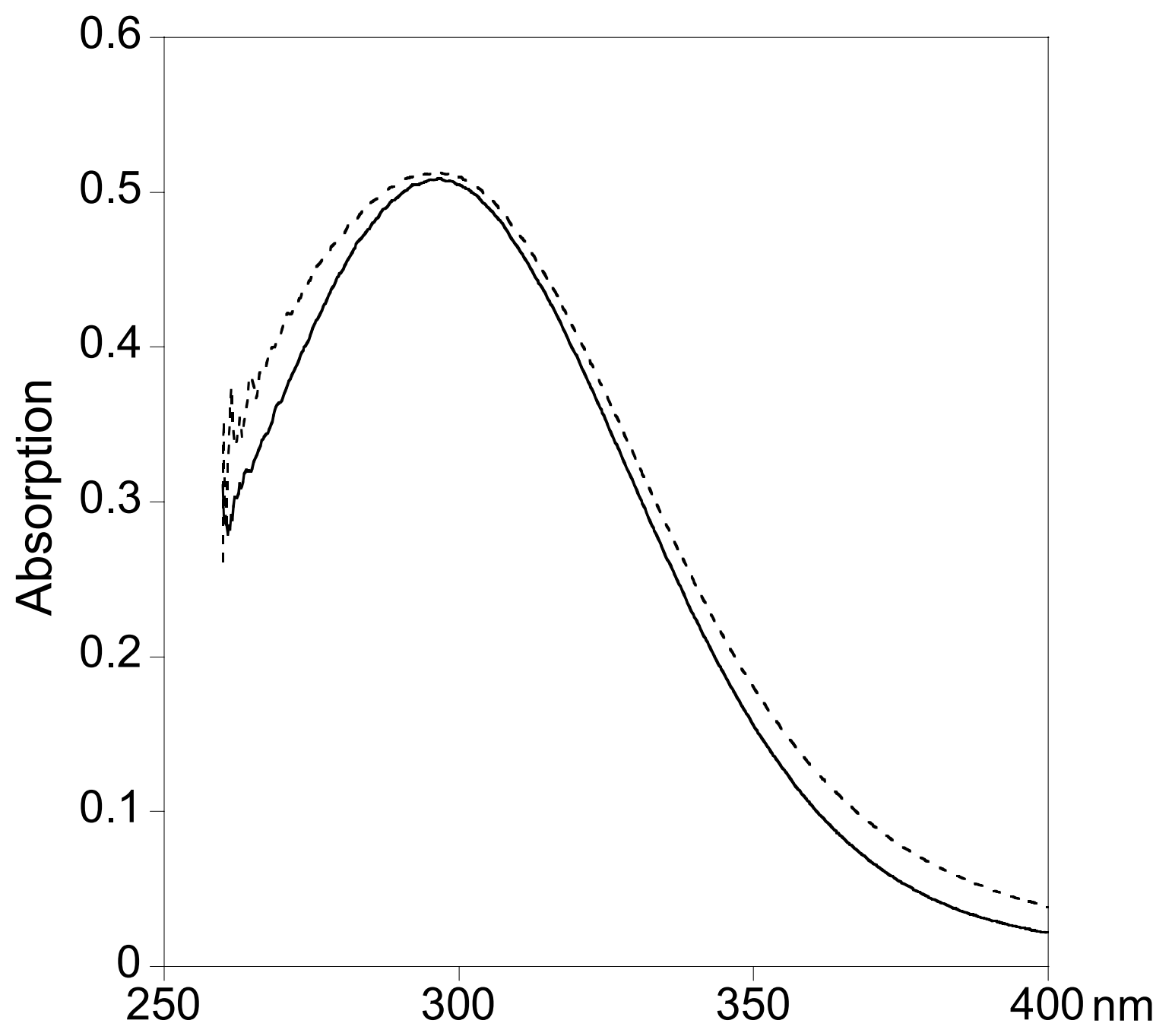

Figure S3. UV spectrum of $(\mathrm{SCN})_{3}{ }^{-}\left(\right.$ca. $\left.100 \mu \mathrm{M}, \varepsilon=7500 \mathrm{~m}^{-1} \mathrm{~cm}^{-1}\right)$ and $(\mathrm{SCN})_{2}(\mathrm{ca} .300$ $\mu \mathrm{M}, \varepsilon=75 \mathrm{~m}^{-1} \mathrm{~cm}^{-1}$ ) produced by oxidation of $500 \mathrm{mM} \mathrm{SCN}^{-}$by $400 \mu \mathrm{M} \mathrm{Cl}_{2}$ (dashed line) and UV spectrum produced by acidification of $400 \mu \mathrm{M} \mathrm{OSCN}^{-}$(solid line) under the same final conditions. 
Scheme S1. Double-mixing sequences that produced the spectra of Figure S3 (top sequence produced the dashed spectrum and bottom sequenced produced the solid spectrum).
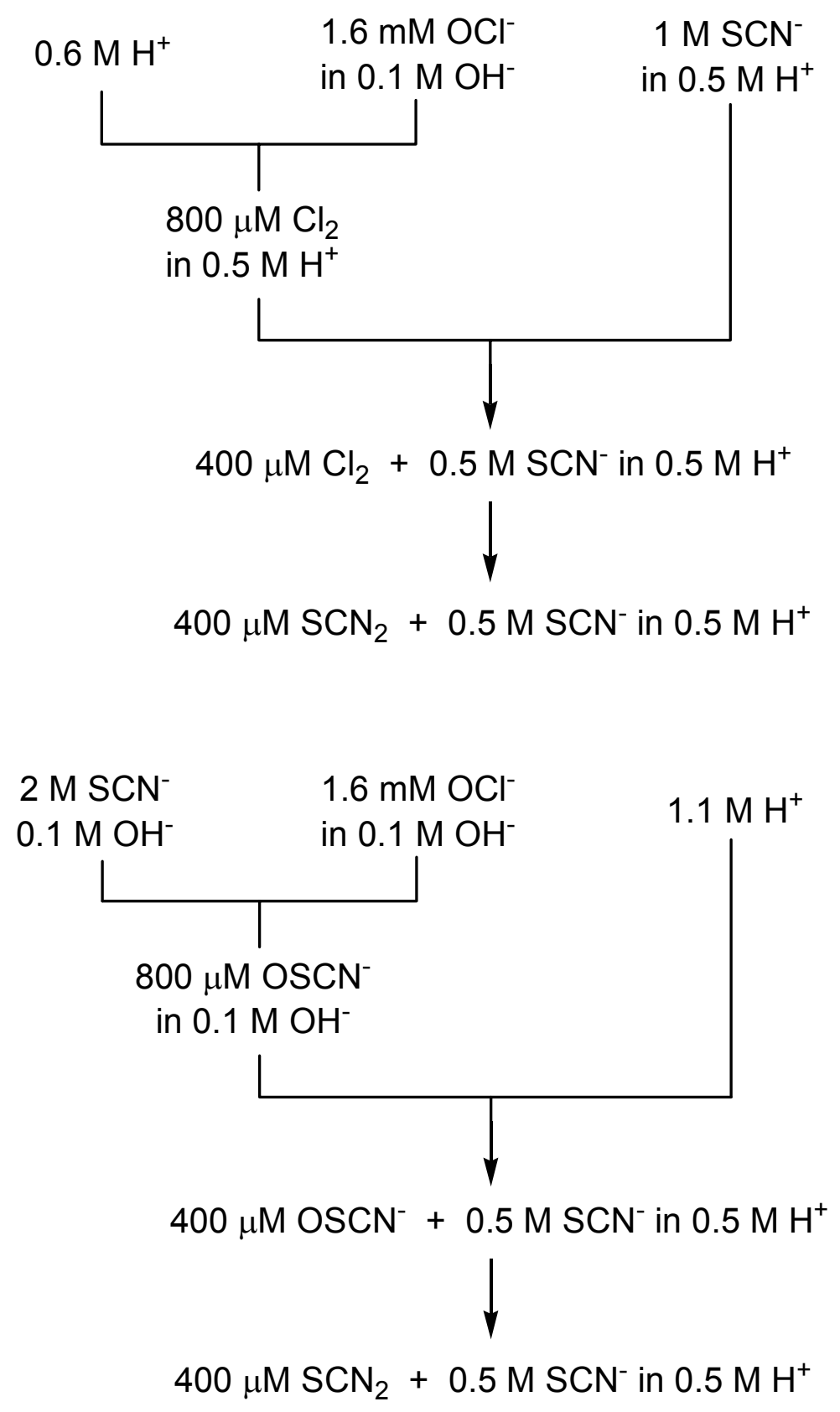
Table S1: Measure Hydroxide Concentrations, ${ }^{\mathrm{a}}$ Computed Proton Concentrations, ${ }^{\mathrm{b}}$, Measured Pseudo-First Order Rate Constants, and Computed Second-Order Rate Constants $\left(\mathrm{M}^{-1} \mathrm{~s}^{-1}\right)^{\mathrm{c}}$ for Oxidation of Thiocyanate $(10 \mathrm{mM})$ by Hypochlorite $(100 \mu \mathrm{M})$ at $25^{\circ} \mathrm{C} .{ }^{\mathrm{d}}$

$\begin{array}{cccc}{\left[\mathbf{O H}^{-}\right]} & {\left[\mathbf{H}^{+}\right]} & \mathbf{k}_{\text {eff }}\left(\mathbf{s}^{-1}\right) & \mathbf{k}_{\mathbf{2}}\left(\mathbf{M}^{-1} \mathbf{s}^{-\mathbf{1}}\right) \mathbf{\times} \mathbf{1 0}^{-7} \\ 5.04 \times 10^{-4} & 3.22 \times 10^{-11} & 195(1) & 2.411 \\ 1.01 \times 10^{-3} & 1.61 \times 10^{-11} & 98.9(2) & 2.446 \\ 2.01 \times 10^{-3} & 8.05 \times 10^{-12} & 48.5(2) & 2.399 \\ 4.03 \times 10^{-3} & 4.03 \times 10^{-12} & 25.2(1) & 2.489 \\ 8.06 \times 10^{-3} & 2.01 \times 10^{-12} & 11.98(2) & 2.373 \\ 1.61 \times 10^{-2} & 1.01 \times 10^{-12} & 5.840(8) & 2.302 \\ 3.22 \times 10^{-2} & 5.03 \times 10^{-13} & 2.885(3) & 2.283 \\ 6.45 \times 10^{-2} & 2.52 \times 10^{-13} & 1.447(1) & 2.286 \\ 1.29 \times 10^{-1} & 1.26 \times 10^{-13} & 0.7159(7) & 2.262 \\ 2.58 \times 10^{-1} & 6.29 \times 10^{-14} & 0.3672(3) & 2.324 \\ 5.16 \times 10^{-1} & 3.14 \times 10^{-14} & 0.1801(3) & 2.283 \\ 1.03 \times 10^{0} & 1.57 \times 10^{-14} & 0.0853(3) & 2.163 \\ & & & k_{2}=2.34(9) \times 10^{7} M^{-1} s^{-1}\end{array}$

${ }^{a}$ Measured by titration against KHP and phenolphthaleine.

${ }^{\mathrm{b}}$ Assuming $\mathrm{pK}_{\mathrm{w}}=13.79$ for $\mu=1$.

${ }^{c}$ See discussion for the kinetic model that was employed.

${ }^{\mathrm{d}}$ Ionic strength $(\mu)$ constant at 1 with $\mathrm{NaCl}$. 
Table S2. Measured Pseudo-First Order Rate Constants and Computed Second-Order Rate Constants $\left(\mathrm{M}^{-1} \mathrm{~s}^{-1}\right)^{\mathrm{c}}$ for Oxidation of Thiocyanate by Hypochlorite $(100 \mu \mathrm{M})$ at $\mathrm{pH}=11.7 .^{\mathrm{a}}$

$\begin{array}{cccc}\mathbf{S C N}^{-}(\mathbf{m M}) & \mathbf{T}\left({ }^{\mathbf{0}} \mathbf{C}\right) & \mathbf{k}_{\text {eff }}\left(\mathbf{s}^{-\mathbf{1}}\right) & \mathbf{k}_{\mathbf{2}}\left(\mathbf{M}^{-\mathbf{1}} \mathbf{s}^{-\mathbf{1}}\right) \mathbf{x} \mathbf{1 0}^{-7} \\ 5 & 25 & 6.52(1) & 2.641 \\ 10 & 25 & 12.71(3) & 2.574 \\ 20 & 25 & 25.94(7) & 2.627 \\ 40 & 25 & 50.4(2) & 2.552 \\ 10 & 37 & 27.47(8) & -\end{array}$

${ }^{\mathrm{a}}$ Assuming $\mathrm{pK}_{\mathrm{w}}=13.79$ for $\mu=1$; ionic strength $(\mu)$ constant at 1 with $\mathrm{NaCl}$. 